\title{
Comparison of Propagation Model Accuracy for Long Term Evolution (LTE) Cellular Network
}

\author{
Sami A. Mawjoud \\ Electrical Engineering Department \\ University of Mosul \\ Mosul, Iraq
}

\begin{abstract}
This paper investigates three different empirical propagation models for the next $4^{\text {th }}$ generation known Long Term Evolution (LTE) in the (2-3) GHz band in urban and suburban areas. The suitability of these models are compared with actual field measurement at $2.6 \mathrm{GHz}$ in Erbil city-Iraq. Tuning method is suggested to fit the experimental results of path loss with the propagation models.
\end{abstract}

\section{Keywords}

Long Term Evolution (LTE), Path Loss Models, Propagation Measurement, Model Tuning.

\section{INTRODUCTION}

Long Term Evolution (LTE) is the $4^{\text {th }}$ generation cellular system. The followings are the main objectives of LTE [1]:

- Increased downlink speed of $100 \mathrm{Mbps}$ and uplink speed of almost $50 \mathrm{Mbps}$.

- The channel will have a scalable bandwidth from $1.3 \mathrm{MHz}$ to $20 \mathrm{MHz}$.

- $\quad$ Supporting both Frequency Division Duplex (FDD) and Time Division Duplex (TDD).

- $\quad$ All IP Network (Flat Network Architecture).

- A standard based interface that can support multitude of users types.

All new wireless systems undergo careful planning [2][3] process, where coverage, capacity and cost-efficiency issues are investigated and optimized. Coverage is an essential part of wireless system design and it is used to verify whether or not the system under design is capable of meeting the given coverage requirements. There are two propagation model techniques:

- Theoretical analysis method based on radio propagation.

- Actual measurement and statistical method based on large amount of test data and empirical formula.

The radial tracking model integrated into the planning software which can be put into commercial use, such as Volcano model and Winprop model, and they are representations of propagation model research through the theoretical analysis method, but this type of model requires a high precision (at least $5 \mathrm{~m}$ ), including 3D digital map of building information. Accuracy of model predication is closely related to the precision and accuracy to digital map.

In the actual and statistical method for propagation model, the most famous statistical model is Okumura model. This model is propagation model represented by curves and was built by okumura based on a large amount of test data collected in Japan. On basis of okumura model, the regression method is used to fit out resolution empirical formula to facilitate computation.

The selection of suitable radio propagation model for LTE is of great importance. The choice of the empirical model accompanied by actual field measurement in the intended area is of vital importance. Therefore path loss measurement and prediction in different areas environment (urban, suburban, etc...) is necessary. Finally, adaption of tuning method is suggested for the theoretical model to fit the experimental results.

\section{PATH LOSS MODELS}

Propagation lo ss $\left(L_{P}\right)$ is the different value between the radiated power $\left(\mathrm{P}_{\mathrm{T}}\right)$ and the received power $\left(\mathrm{P}_{\mathrm{R}}\right)$.

$\mathrm{L}_{\mathrm{P}}(\mathrm{dB})=\mathrm{P}_{\mathrm{T}}-\mathrm{P}_{\mathrm{R}}$

\subsection{Okumura-Hata Model}

Okumura-Hata model [4] uses empirical data to determine the path loss $\left(\mathrm{L}_{\mathrm{P}}\right)$ in $\mathrm{dB}$ given by equation (2).

$\mathrm{L}_{\mathrm{P}(\text { urban })}(\mathrm{dB})=69.55+26.16 \log _{10}\left(\mathrm{f}_{\mathrm{c}}\right)-13.82 \log _{10}\left(\mathrm{~h}_{\mathrm{b}}\right)-\mathrm{a}\left(\mathrm{h}_{\mathrm{m}}\right)$
$+\left(44.9-6.55 \log _{10}\left(\mathrm{~h}_{\mathrm{b}}\right)\right) \log _{10}(\mathrm{~d})$

Where fc: is the frequency in $\mathrm{MHz}$

$\mathrm{h}_{\mathrm{b}}$ : is the BTS effective transmitter antenna height in meter.

$\mathrm{h}_{\mathrm{m}}$ : is the effective mobile receiver antenna height in meter.

$\mathrm{d}$ : is the distance between Base Station (Bs) and the Mobile Station (Ms) in Kilometers.

$\mathrm{a}\left(\mathrm{h}_{\mathrm{m}}\right)$ : is the correction factor for effective Ms antenna height which is a function of the size of the coverage area. where the correction factor $\mathrm{a}\left(\mathrm{h}_{\mathrm{m}}\right)$ for suburban and rural area is

$$
\mathrm{a}\left(\mathrm{h}_{\mathrm{m}}\right)=\left(1.1 \log _{10}\left(\mathrm{f}_{\mathrm{c}}\right)-0.7\right) \mathrm{h}_{\mathrm{m}}-\left(1.56 \log _{10}\left(\mathrm{f}_{\mathrm{c}}\right)-0.8\right)
$$

For Urban area the correction factor $\mathrm{a}\left(\mathrm{h}_{\mathrm{m}}\right)$ is

$$
\begin{array}{r}
a\left(h_{m}\right)=823\left(\underline{\log }_{10}\left(1.54 h_{m}\right)\right)^{2}-1.1 \quad \text { for } \quad f_{c}<300 \mathrm{MHz} \\
\ldots(4) \\
a\left(h_{m}\right)=3.2\left(\log _{10}\left(11.75 h_{m}\right)\right)^{2}-4.97 \quad \text { for } f_{c}>300 \mathrm{MHz}
\end{array}
$$

The path loss for Suburban area is:

$\mathrm{L}_{\mathrm{P}(\text { Suburban })}(\mathrm{dB})=\mathrm{L}_{\mathrm{P}(\text { urban })}-2 \log _{10}(\mathrm{fc} / 28)^{2}-5.4$

And the path loss for open area is: $\begin{aligned} L_{P(\text { Open })}(d B)= & L_{P(\text { urban })}-4.78 \log _{10}\left(f_{c}\right)^{2}+18.33 \log _{10}\left(f_{c}\right) \\ & -40.94\end{aligned}$

The limitations of Okumura-Hata model are:

$\mathrm{f}=150-1500 \mathrm{MHz}, \mathrm{h}_{\mathrm{b}}=30-300 \mathrm{~m}, \mathrm{~h}_{\mathrm{m}}=1-10 \mathrm{~m}, \mathrm{~d}=1-20 \mathrm{~km}$. 


\subsection{Cost-231 Okumura-Hata Model}

An extension of Okumura-Hata model is the cost-231 Hata model [5][6]. The model extends the frequency range up to $2000 \mathrm{MHz}$

$\mathrm{L}_{\mathrm{p}(\text { cost-321) }}(\mathrm{dB})=46.3+33.9 \log _{10}\left(\mathrm{f}_{\mathrm{c}}\right)-13.82 \log _{10}\left(\mathrm{~h}_{\mathrm{b}}\right)-\mathrm{a}\left(\mathrm{h}_{\mathrm{m}}\right)$
$+\left(44.9-6.55 \log _{10}\left(\mathrm{~h}_{\mathrm{b}}\right)\right) \log _{10}(\mathrm{~d})+\mathrm{C}_{\mathrm{m}} \ldots(8)$

For large city (urban area) the correction factor $\mathrm{a}\left(\mathrm{h}_{\mathrm{m}}\right)$ is given by Eq. (5). While $\mathrm{a}\left(\mathrm{h}_{\mathrm{m}}\right)$ for suburban or rural areas is given by Eq. (3).

$\mathrm{C}_{\mathrm{m}}=0$ for median sized cities and suburban areas.

$\mathrm{C}_{\mathrm{m}}=3 \mathrm{~dB}$ for metropolitan areas

\subsection{SUI Model}

Stanford University Intern (SUI) model [7] is developed for IEEE 802.16 Broadband wireless access working group. It is suited for frequencies above $1900 \mathrm{MHz}$. The main difference from other models is that the path loss exponent is treated as a random variable in addition to the shadowing effects. The basic path loss $\left(\mathrm{P}_{\mathrm{L}}\right)$ of this model along with its correction factors is given as:

$$
P_{L}(d B)=A+10 \Upsilon \log _{10}\left(d / d_{o}\right)+X_{f}+X_{h}+S
$$

Where: $\mathrm{P}_{\mathrm{L}}$ is the path loss in $\mathrm{dB}$

A is the free space path loss given as:

$$
A=20 \log _{10}\left(4 \pi d_{o} / \lambda\right)
$$

Where $d_{o}$ is the reference distance 100 meters from the Bs

$$
\Upsilon=a-b h_{b}+c / h_{b}
$$

Where: $h_{b}$ is the height of base station and $(a, b, c)$ represent the terrain for which the values are selected as shown in table (1).

$\mathrm{X}_{\mathrm{f}}$ is the correction factor for frequency given as

$$
X_{\mathrm{f}}=6 \log _{10}(\mathrm{f} / 2000)
$$

$\mathrm{X}_{\mathrm{h}}$ is the correction factor for Bs height given as

$$
\mathrm{X}_{\mathrm{h}}=-10.8 \log _{10}\left(\mathrm{~h}_{\mathrm{r}} / 2000\right)
$$

$\mathrm{h}_{\mathrm{r}}$ is the height of Ms receiver antenna and $\mathrm{f}$ in $\mathrm{MHz}$.

$\mathrm{X}_{\mathrm{h}}$ in Eq. (14) is used for terrain type A and B. For terrain C the below expression is used.

$$
\mathrm{X}_{\mathrm{h}}=-20 \log _{10}\left(\mathrm{~h}_{\mathrm{r}} / 2000\right)
$$

Table (1) SUI model numerical values for different terrain categories.

\begin{tabular}{|c|c|c|c|}
\hline $\begin{array}{c}\text { Mode } \\
\text { Parameters }\end{array}$ & $\begin{array}{c}\text { Terrain A } \\
\text { (hilly/moderate } \\
\text { to heavy tree } \\
\text { density) }\end{array}$ & $\begin{array}{c}\text { Terrain B } \\
\text { (hilly/light tree } \\
\text { density of flat } \\
\text { / moderate to } \\
\text { heavy tree } \\
\text { density) }\end{array}$ & $\begin{array}{c}\text { Terrain C } \\
\text { (flat/light } \\
\text { tree } \\
\text { density) }\end{array}$ \\
\hline $\mathrm{a}$ & 4.6 & 4.0 & 3.6 \\
\hline $\mathrm{b}\left(\mathrm{m}^{-1}\right)$ & 0.0076 & 0.0065 & 0.005 \\
\hline $\mathrm{c}$ & 12.6 & 17.1 & 20 \\
\hline
\end{tabular}

\subsection{Log-Distance Propagation Model}

The power law path loss model [8][9] is one of the simplest path loss model to be used it consists of two propagation environment related parameters and two reference parameter which are used to adjust the model to the corresponding propagation environment. The path loss $\mathrm{P}_{\mathrm{L}(\mathrm{d})}$ is used to predict the mean path loss values and is given below.

$$
\mathrm{P}_{\mathrm{L}(\mathrm{d})}(\mathrm{dB})=\mathrm{P}_{\mathrm{L}(\mathrm{do})}+10 \mathrm{n} \log _{10}\left(\mathrm{~d} / \mathrm{d}_{\mathrm{o}}\right)
$$

$P_{L(d o)}$ is the reference path loss at reference distance $\left(d_{o}\right)$ in $\mathrm{dB}$.

$\mathrm{n}$ is a variable represent the propagation exponent fading variation over the mean path loss value. The reference path loss value is approximated either using free space path loss formula or through field measurements at distance $d_{0}$. The propagation environment related parameter $\mathrm{n}$ and the center frequency, the propagation environment and the antenna height are given.

The propagation exponent $\mathrm{n}$ is typically used to classify propagation environment and it describes how quickly the signal level attenuates as a function of distance.

\section{PROPAGATION MODEL TUNING}

The purpose of propagation model tuning is to minimize the error between the predicted path loss values and the measurements [9][10].

\subsection{Cost-231 Hata Model Tuning}

Linear Least Squares Method (LLSM) can be used to achieve a minimum mean error and acceptable standard deviation (Std) between measure and predict path loss [11][12]. The mathematical analysis of LLSM is shown as below[13][14].

First, defined the parameters of all equations used below which are:

$\mathrm{L}_{\mathrm{P}}$ is the theoretical path loss from Hata Model. $\mathrm{L}_{\mathrm{m}}$ is measured path loss. $\Delta \mathrm{L}$ is the difference between predicted and measured path loss. $A_{1}$ is additional factor for constant attenuation. $\mathrm{A}_{2}$ is additional factor for attenuation about distance (d). $\mathrm{L}_{\text {tuned }}$ is the tuned Hata propagation model after modification for each terrain environment.

Eq. (8) can be written as :

$$
\begin{gathered}
\mathrm{L}_{\mathrm{P}}(\mathrm{dB})=\mathrm{K}_{1}+33.9 \log _{10}(\mathrm{f})-13.82 \log _{10}\left(\mathrm{~h}_{\mathrm{b}}\right)-\mathrm{a}\left(\mathrm{h}_{\mathrm{m}}\right) \\
+\mathrm{K}_{2} \log _{10}(\mathrm{~d})+\left(-6.55 \log _{10}\left(\mathrm{~h}_{\mathrm{b}}\right) \log _{10}(\mathrm{~d})\right)+\mathrm{C}_{\mathrm{m}}
\end{gathered}
$$

By adding $A_{1}$ and $A_{2}$ factors for tuning purpose, the $L_{\text {tuned }}$ equation can be written as:

$\mathrm{L}_{\text {tuned }}(\mathrm{dB})=\left(\mathrm{K}_{1}+\mathrm{A}_{1}\right)+33.9 \log _{10}(\mathrm{f})-13.82 \log _{10}\left(\mathrm{~h}_{\mathrm{b}}\right)-\mathrm{a}\left(\mathrm{h}_{\mathrm{m}}\right)$ $+\left(\mathrm{K}_{2}+\mathrm{A}_{2}\right) \log _{10}(\mathrm{~d})+\left(-6.55 \log _{10}\left(\mathrm{~h}_{\mathrm{b}}\right) \log _{10}(\mathrm{~d})\right)+\mathrm{C}_{\mathrm{m}} \quad \ldots(17)$

Reasoning for only $K_{1}$ and $K_{2}$ is that for each test of a certain station $\mathrm{f}, \mathrm{h}_{\mathrm{b}}, \mathrm{h}_{\mathrm{m}}$ are all fixed values but the distance is variable [9].

$\Delta \mathrm{L}=\left(\mathrm{L}_{\mathrm{P}}-\mathrm{L}_{\mathrm{m}}\right)$

The error equation can be written as :

$$
E\left(A_{1}, A_{2}\right)=\sum_{i=1}^{n}\left(\Delta L_{i}-\left(A_{1}+A_{2} \log _{10} d_{i}\right)\right)^{2}
$$

Where: $\mathrm{n}$ is the No. of measurements samples. 
By using LLSM to find the values of $A_{1}$ and $A_{2}$ to obtain a lower value of $\mathrm{E}\left(\mathrm{A}_{1}, \mathrm{~A}_{2}\right)$.

$$
\frac{\partial \mathrm{E}}{\partial \mathrm{A}_{1}} \cong 0 \quad \text { and } \quad \frac{\partial \mathrm{E}}{\partial \mathrm{A}_{2}} \cong 0
$$

By solving Eq.(19) the result is:

$$
\begin{aligned}
& \left(\sum_{i=1}^{n} \log _{10} d_{i}\right) A_{1}+\left(\sum_{i=1}^{n}\left(\log _{10} d_{i}\right) i^{2}\right) A_{2}=\sum_{i=1}^{n} \Delta L_{i} \log _{10} d_{i} \\
& \left(\sum_{i=1}^{n}(1)\right) A_{1}+\left(\sum_{i=1}^{n} \log _{10} d_{i}\right) A_{2}=\sum_{i=1}^{n} \Delta L_{i} . .(21)
\end{aligned}
$$

From Eq.(20) and Eq. (21) result a matix equation :

$$
\left(\begin{array}{l}
A_{1} \\
A_{2}
\end{array}\right)=\left(\begin{array}{ll}
\sum_{i=1}^{n} \log _{10} d_{i} & \sum_{i=1}^{n}\left(\log _{10} d_{i}\right)^{2} \\
\sum_{i=1}^{n}(1) & \sum_{i=1}^{n} \log _{10} d_{i}
\end{array}\right)^{-1}\left(\begin{array}{c}
\sum_{i=1}^{n} \Delta L_{i} \log _{10} d_{i} \\
\sum_{i=1}^{n} \Delta L_{i}
\end{array}\right)
$$

\subsection{SUI Propagation Model Tuning}

The mathematical analysis of SUI tuning using Carmer's method is shown below.

Eq. (10) can be written as:

$\mathrm{P}_{\mathrm{L}}(\mathrm{dB})=\mathrm{C}+\mathrm{nB}+\mathrm{S}$

Where: $S$ is the correction factor, $B=10 \log _{10}\left(d / d_{0}\right), d_{o}=100 m$, $\mathrm{C}=\mathrm{A}+\mathrm{X}_{\mathrm{f}}+\mathrm{X}_{\mathrm{h}}$.

$E(B, S)=\sum_{i=1}^{n}\left(P_{L_{i}}-L_{m_{i}}\right)^{2}$

$\frac{\partial \mathrm{E}}{\partial B} \cong 0 \quad$ and $\quad \frac{\partial \mathrm{E}}{\partial S} \cong 0$

Eq. (24) can be solved using Carmer's determinant based method.

$\mathrm{n} \mathrm{B}_{\mathrm{i}}+\mathrm{S}=\mathrm{L}_{\mathrm{mi}}-\mathrm{C}$...(26)

$\left(\begin{array}{l}\mathrm{n} \\ \mathrm{S}\end{array}\right)=\left(\begin{array}{ll}\mathrm{B}_{1} & 1 \\ \mathrm{~B}_{\mathrm{n}} & 1\end{array}\right)^{-1} *\left(\begin{array}{c}\mathrm{L}_{\mathrm{m} 1}-\mathrm{C} \\ \mathrm{L}_{\mathrm{mn}}-\mathrm{C}\end{array}\right)$

\subsection{Log-Distance Propagation Model Tuning}

The mathematical analysis of log-distance tuning model using Carmer's method is shown below. Eq. (16) can be written as:

$\mathrm{P}_{\mathrm{L}}(\mathrm{dB})=\mathrm{A}+\mathrm{n} \mathrm{B}$

Where: $\mathrm{A}$ is free space path loss given in Eq. (11), $B=10 \log _{10}\left(d / d_{o}\right), d_{o}=100 m$.

$E(n)=\sum_{i=1}^{n}\left(P_{L_{i}}-L_{m_{i}}\right)^{2}$

$n \mathrm{~B}_{\mathrm{i}}=\mathrm{L}_{\mathrm{mi}}-\mathrm{A}$
$(\mathrm{n})=\left(\begin{array}{l}\mathrm{B}_{1} \\ \mathrm{~B}_{\mathrm{n}}\end{array}\right)^{-1} *\left(\begin{array}{c}\mathrm{L}_{\mathrm{ml}}-\mathrm{A} \\ \mathrm{L}_{\mathrm{mn}}-\mathrm{A}\end{array}\right)$

The verification statistical parameters which used in this paper are Mean Error (ME), Root Mean Square Error (RMSE) and Standard deviation (Std)[2][10].

$$
\begin{aligned}
& \operatorname{ME}(\mathrm{dB})=\frac{1}{\mathrm{n}} \sum_{\mathrm{i}=1}^{\mathrm{n}}\left(\mathrm{L}_{\mathrm{Pi}}-\mathrm{L}_{\mathrm{mi}}\right) \\
& \operatorname{RMSE}(\mathrm{dB})=\sqrt{\frac{1}{\mathrm{n}} \sum_{\mathrm{i}=1}^{\mathrm{n}}\left(\mathrm{L}_{\mathrm{Pi}}-\mathrm{L}_{\mathrm{mi}}\right)^{2}} \\
& \operatorname{Std}(\mathrm{dB})=\sqrt{\operatorname{RMSE}-(\mathrm{ME})^{2}}
\end{aligned}
$$

\section{MEASUREMENTS PROSCEDURE}

The aim of radio measurement is to measure the signal strength transmitted from a test transmitter by a receiver at different distance within coverage area. The radio measurement data files are used to optimize the parameters in the path loss prediction model to achieve optimal predicted signal level compared to measured signal level. The measurements procedure included the following:

- Define models required to recreate coverage of different physical environments: such as a Cost-321 Hata, SUI, Log-distance models which are chosen for tuning process in this paper.

- Site selection survey to find suitable sites for each environment: the location of test site have been selected carefully in order to cover each dominant clutter types Urban and Suburban in Erbil city as shown in fig(1) and(2).

- Tx and Rx equipment: Table (2) show the parameters of two Bss, the received equipment is a Test Mobile System Measurement Unit which is known (TEMS Investigation) as a data collection software tool is used. TEMS is designed for signal strength measurement and a lap-top computer it was used to control TEMS unit (USB Modem) and to store the measured data with Global position System (GPS) having external antenna.

- Assessment and preparation of data collection: Before the collected data can be used, appropriate filtering was performed to verify its validity and remove erroneous data. A distance filtering has been applied minimum distance $50 \mathrm{~m}$ and maximum distance $2 \mathrm{~km}$. an additional signal strength filtering has been performed to collected data, the signal range applied is (-40 to -120$) \mathrm{dBm}$.

Table(2) Base Station Parameters

\begin{tabular}{|l|c|c|}
\hline Bs Name & Bs1_urban & Bs2_suburban \\
\hline Antenna Gain & $18 \mathrm{~dB}$ & $18 \mathrm{~dB}$ \\
\hline Antenna Height & $35 \mathrm{~m}$ & $28.3 \mathrm{~m}$ \\
\hline Antenna Downtilt & $6^{\circ}$ & $7^{\circ}$ \\
\hline Frequency Band & $2600 \mathrm{MHz}$ & $2600 \mathrm{MHz}$ \\
\hline Channel Bandwidth & $20 \mathrm{MHz}$ & $20 \mathrm{MHz}$ \\
\hline Max Tx Power & $46.2 \mathrm{dBm}$ & $46.2 \mathrm{dBm}$ \\
\hline UE Sensitivity & $-115 \mathrm{dBm}$ & $-115 \mathrm{dBm}$ \\
\hline
\end{tabular}




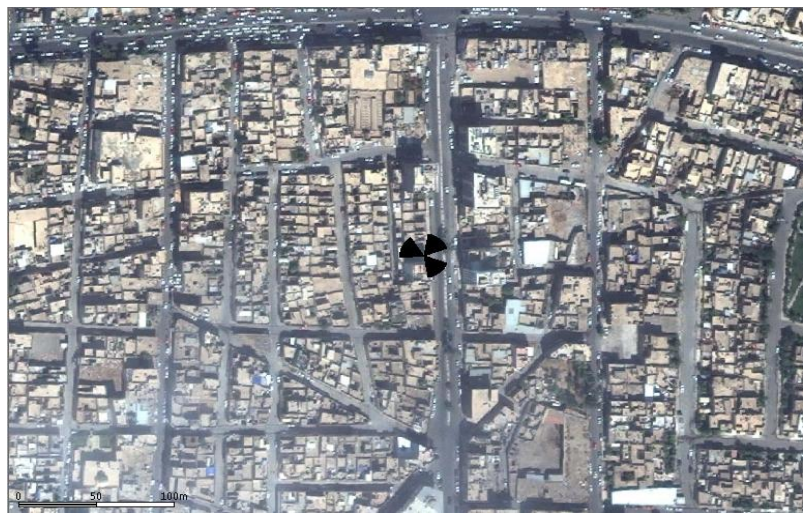

Fig (1) Site 1 in Urban area

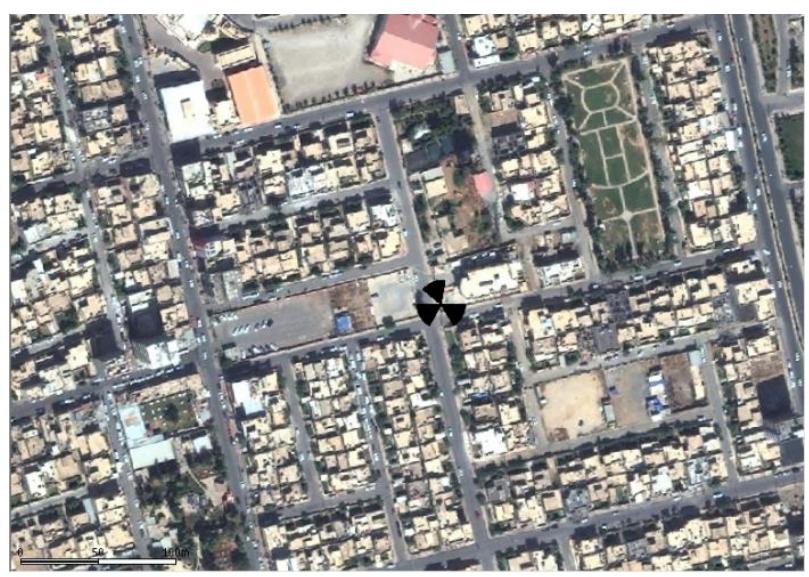

Fig (2) Site 2 in Suburban area

\section{RESULTS AND DISCUSSION}

To verify the proposed mathematical models for different propagation models tuning, a comparison between predicted path loss and measured path loss data have been carried out for LTE site (operating at $2.6 \mathrm{GHz}$ ) for urban and suburban environments in Erbil city.

For verification and comparison between the tuned propagation models in order to find the close fitting model to measure data. Statistical parameters mean error, root mean square error and standard deviation have been considered.

Fig (3) and Fig (4) show comparison between the measured data and predicted path loss for Cost-231 Hata, SUI and Logdistance models as a function of distance. It can be observed from fig(3) and fig(4) that the optimum model which is close to the measured path loss is the tuned Cost-231 Hata model which have lowest mean error (ME) reaching zero as compared to other propagation models. Tables $(3,4,6)$ represent the results of the statistical tuning process for each model.

The tuned SUI model also have good performance with mean error $0.32 \mathrm{~dB}$, the tuned $\log$-distance model have the lowest performance as compared to other models but it is still acceptable from the practical view of tuning process because the mean error is lower than $1 \mathrm{~dB}$. From tables $(3,4,6)$ it can be concluded that the mathematical models which used are suitable for tuned propagation models because all tuned model (SUI, Cost-231 Hata, Log-distance) have lower mean error and acceptable standard deviation, as in table(5) which represent the value of parameters before tuning and table (6).

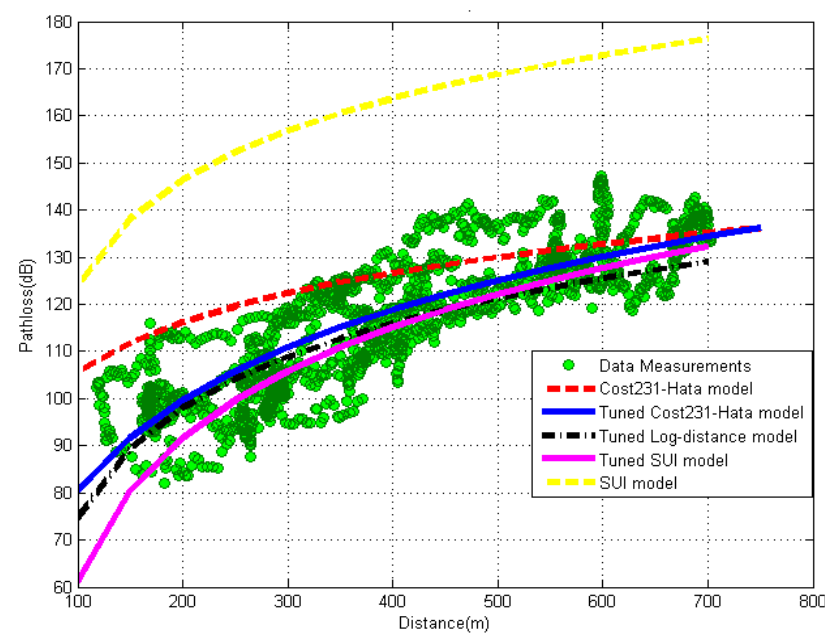

Fig(3) Comparison of the optimized Path loss with measured data for urban area site.

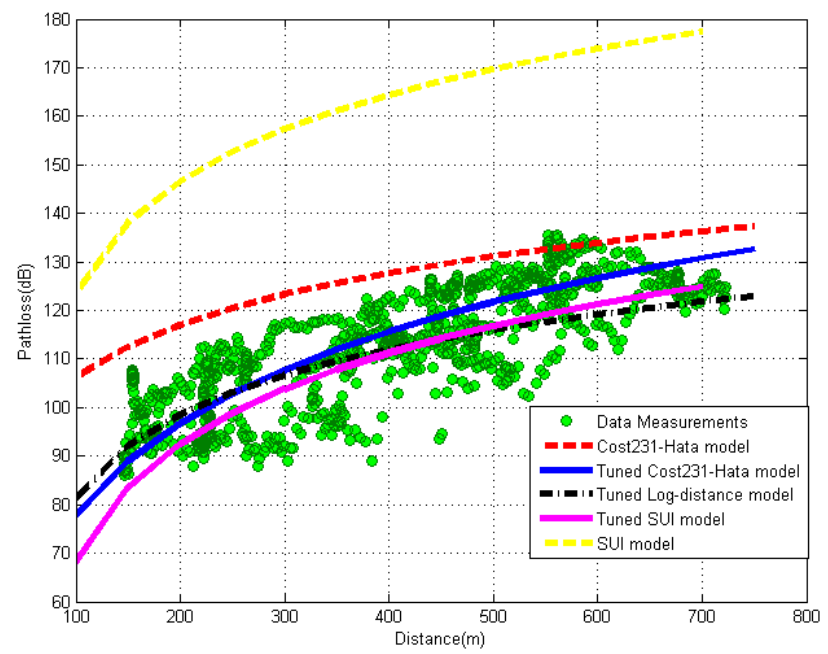

Fig(4) Comparison of the optimized Path loss with measured data for suburban area site.

Table (3) Log-Distance Propagation Model Parameters.

\begin{tabular}{|l|c|l|l|c|}
\hline Clutter Class & $\begin{array}{l}\text { Pathloss } \\
\text { Exponent } \\
(\mathrm{n})\end{array}$ & $\begin{array}{l}\text { Mean } \\
\text { Error } \\
{[\mathrm{dB}]}\end{array}$ & $\begin{array}{l}\text { Mean } \\
\text { Std. } \\
{[\mathrm{dB}]}\end{array}$ & $\begin{array}{l}\text { RMSE } \\
{[\mathrm{dB}]}\end{array}$ \\
\hline Urban Area & 4.8 & -0.68 & 8.3 & 8.5 \\
\hline Suburban Area & 3.6 & $0.43-$ & 7.81 & 7.82 \\
\hline
\end{tabular}

Table (4) SUI Propagation Model Parameters After Tuning Process

\begin{tabular}{|l|c|c|c|c|c|}
\hline $\begin{array}{l}\text { Clutter } \\
\text { Class }\end{array}$ & $\begin{array}{l}\text { Pathloss } \\
\text { Exponent } \\
(\mathrm{n})\end{array}$ & $\begin{array}{l}\text { Correction } \\
\text { Factor (S) } \\
{[\mathrm{dB}]}\end{array}$ & $\begin{array}{l}\text { Mean } \\
\text { Error } \\
{[\mathrm{dB}]}\end{array}$ & $\begin{array}{l}\text { Mean } \\
\text { Std. } \\
{[\mathrm{dB}]}\end{array}$ & $\begin{array}{l}\text { RMSE } \\
{[\mathrm{dB}]}\end{array}$ \\
\hline $\begin{array}{l}\text { Urban } \\
\text { Area }\end{array}$ & 6.38 & -68 & 0.32 & 8.83 & 8.82 \\
\hline $\begin{array}{l}\text { Suburban } \\
\text { Area }\end{array}$ & 5 & -65 & 0.21 & 8.3 & 8.28 \\
\hline
\end{tabular}


Table (5) Cost231-Hata Propagation Model Parameters Before Tuning Process.

\begin{tabular}{|l|c|c|c|c|c|}
\hline $\begin{array}{l}\text { Clutter } \\
\text { Class }\end{array}$ & $\begin{array}{l}\text { Correction } \\
\text { Factor k1 } \\
{[\mathrm{dB}]}\end{array}$ & $\begin{array}{l}\text { Correction } \\
\text { Factor k2 } \\
{[\mathrm{dB}]}\end{array}$ & $\begin{array}{l}\text { Mean } \\
\text { Error } \\
{[\mathrm{dB}]}\end{array}$ & $\begin{array}{l}\text { Mea } \\
\mathrm{n} \\
\begin{array}{l}\text { Std. } \\
{[\mathrm{dB}]}\end{array}\end{array}$ & $\begin{array}{l}\text { RMSE } \\
{[\mathrm{dB}]}\end{array}$ \\
\hline $\begin{array}{l}\text { Urban } \\
\text { Area }\end{array}$ & 46.3 & 44.9 & -9.2 & 9.6 & 13.4 \\
\hline $\begin{array}{l}\text { Suburban } \\
\text { Area }\end{array}$ & 46.3 & 44.9 & -14 & 7.8 & 16 \\
\hline
\end{tabular}

Table (6) Cost231-Hata Propagation Model Parameters After Tuning Process.

\begin{tabular}{|l|c|c|c|c|c|}
\hline $\begin{array}{l}\text { Clutter } \\
\text { Class }\end{array}$ & $\begin{array}{l}\text { Correction } \\
\text { Factor k1 } \\
{[\mathrm{dB}]}\end{array}$ & $\begin{array}{l}\text { Correction } \\
\text { Factor k2 } \\
{[\mathrm{dB}]}\end{array}$ & $\begin{array}{l}\text { Mean } \\
\text { Error } \\
{[\mathrm{dB}]}\end{array}$ & $\begin{array}{l}\text { Mean } \\
\text { Std. } \\
{[\mathrm{dB}]}\end{array}$ & $\begin{array}{l}\text { RMSE } \\
{[\mathrm{dB}]}\end{array}$ \\
\hline $\begin{array}{l}\text { Urban } \\
\text { Area }\end{array}$ & 49.82 & 73.9 & 0 & 7.8 & 7.85 \\
\hline $\begin{array}{l}\text { Suburban } \\
\text { Area }\end{array}$ & 43.8 & 72.2 & -0.0037 & 7.63 & 7.6 \\
\hline
\end{tabular}

\section{CONCLUSION}

In this paper a proposed optimization method of path loss models using least square method is presented. The models tuning have be excuted to fit empirical path loss models to actual field measurements. Analytical and measured results concluded that the performance of tuned Cost-231 Hata model is the best among other considered models. The mean error of the cost-231 Hata model for urban area is reduced to zero, the mean standard deviation value is reduced to $7.8 \mathrm{~dB}$ and the root mean square error reduced to $7.85 \mathrm{~dB}$. Hence the Cost231 Hata model is recommended to be used for propagation prediction in Erbil city.

\section{REFERENCES}

[1] LTE an Introduction, White paper, Ericsson AB, 2009.

[2] L. Kalzar, J. Prokopec, "Propagation Path Loss Models For Mobile Communication", IEEE International Conference Radioelektronika, 2011.

[3] M. Didarul and M. Razaul, " Comparison Study of Path Loss Models of WiMAX at $2.5 \mathrm{GHz}$ Frequency Band", International Journal of Future Communication and Networking, Vol. 6, No. 2, April 2013.
[4] Hata M., "Empirical Formula For Propagation Loss in Land Mobile Radio Services", IEEE Transaction on Vechicular Technology Vol. 29, No. 3, 1980.

[5] Goldsmith A., " Wireless Communication", USA, Cambridge University Press, 2005.

[6] A. Yawardhana, V. Wassel, J. Closby, D. Sellars, M. Brown, " Comparison of Empirical Propagation Path Loss Models For Fixed Wireless Access Systems", Proceeding of the 61 IEEE Vehicular technology conference, 2005

[7] N. Shabbit, M. Saidq, H. Kashif, and R.Ullah, " Comparison of Radio Propagation Models For Long Term Evolution (LTE) Network", International Journal of Next generation networks, Vol. 3, No. 3, September 2011.

[8] M. Lanovic, S. Rimac, and K. Bejuk, " Comparison of Propagation Models Accuracy for WiMAX on $3.5 \mathrm{GHz}$, IEEE International Conference on Electronics, 2007.

[9] J. Demertriow, R. Mackenzi. " Propagation Basics", September 30, 1998, pp. 39-42. Available online on www.scribd.com/doc/7218261/Propagation-Basics.

[10] B. Yesin, I. Hakki, " Mobile Radio Propagation Measurements and Tuning the Path Loss Model in urban Area at GSM-900 Band Istanbul-Turkey", Fall $60^{\text {th }}$ Vehicular Technology conference, No. 6, Los Angeles CA, 2004.

[11] M. Yang, W. Shi, " A linear Least Square Method for Propagation Model Tuning for 3G Radio Network Planning", Fourth International Conference on neutral Computation, IEE Computer Society, Vol. 5, pp. 150154, 2008.

[12] K. Diawuo, T. Cemberbatch, " Data Fitting to Propagation Model Using Least Square Algorithm: A Case Study in Ghana", International Journal of Engineering Science, Vol. 2, No. 6, June 2013.

[13] B. Castro, M. Pinheiro, G. Canalcante, " Comparison Between Known propagation Models Using Least Square Tuning Algorithm on $5.8 \mathrm{GHz}$ in Amazon Region Cities", Journal of Microwaves, Optoelectronics Application, Vol. 10, No. 1, June 2011.

[14] Simi I., Santi I., and Zermi B.," Minimax LS Algorthim for Automatic Propagation Model Tuning" Proceeding of the 9th Telecommunications Forum (TELFOR 2001), Belgrade, Nov 2001. 